\title{
Acquired subglottic stenosis caused by methicillin resistant Staphylococcus aureus that produce epidermal cell differentiation inhibitor
}

\author{
Y Yamada, M Sugai, M Woo, N Nishida, T Sugimoto
}

\begin{abstract}
Local infection of the trachea in intubated neonates is one of the main risk factors for development of acquired subglottic stenosis, although its role in the pathogenesis is unclear. Methicillin resistant Staphylococcus aureus (MRSA) is often the cause of critical illness in neonatal patients. Two cases are reported of acquired subglottic stenosis following bacterial infection of the trachea, suggesting an association with the staphylococcal exotoxin, epidermal cell differentiation inhibitor (EDIN). EDIN-producing MRSA were isolated from purulent tracheal secretions from both infants. Acquired subglottic stenosis in both cases was probably caused by delayed wound healing as the result of EDIN inhibition of epithelial cell migration.
\end{abstract}

(Arch Dis Child Fetal Neonatal Ed 2001;84:F38-F39)

Keywords: acquired subglottic stenosis; epidermal cell differentiation inhibitor; methicillin resistant Staphylococcus aureus; neonates; neonatal toxic shock syndromelike exanthematous disease

Acquired subglottic stenosis (ASGS) is a recognised complication of endotracheal intubation in neonates, with a reported incidence of between $1 \%$ and $8 \% .^{1-3}$ The risk factors for development of ASGS include size of the endotracheal tube relative to the patient's larynx, a long duration of intubation, motion of the tube, traumatic intubation, and the frequency of intubations. In addition, patient factors, which include the activity of the patient, systemic infection and illness, hypoxia, episodic hypotension, local infection of the larynx, shape or size of the individual larynx, and wound healing, play an important role..$^{1-4}$

Recently, epidermal cell differentiation inhibitor (EDIN) was purified to homogeneity from extracellular products of Staphylococcus aureus. ${ }^{5}$ It has been shown to inhibit the terminal differentiation of human keratinocytes in culture and simulates proliferation of the cells. ${ }^{6}$

Here we describe two neonates with ASGS following bacterial infection of the trachea, and speculate that ASGS in both cases was caused by delayed wound healing as the result of EDIN inhibition of epithelial cell migration.

\section{Case reports}

CASE 1

A baby girl weighing $3055 \mathrm{~g}$ was delivered by caesarean section at 37 weeks of gestation. An endotracheal tube was inserted, and assisted ventilation was started because of transient tachypnoea of the newborn. At 3 days of age, the patient developed fever, measles-like exanthema, and thrombocytopenia. A diagnosis of neonatal toxic shock syndrome-like exanthematous disease (NTED) was made. Empiric antibiotic treatment was started. At 5 days of age the patient showed a yellowish tracheal secretion, and the glottis was red but not swollen. A diagnosis of acute laryngotracheitis was made. At the same time, EDIN-producing MRSA were isolated from the tracheal secretions but not from blood culture. Systemic symptoms resolved within a few days. At 13 days of age, extubation was performed; however, the patient was reintubated soon after because of stridor and retraction, which disappeared rapidly on intubation without ventilatory assistance or oxygen. Similar episodes occurred several times despite adrenaline (epinephrine) inhalation and systemic steroids. Subglottic stenosis by granulation tissue was disclosed by a bronchoscopy, and tracheotomy was performed.

\section{CASE 2}

A baby girl weighing $2790 \mathrm{~g}$ was delivered by caesarean section at 37 weeks of gestation. At three hours after birth, the trachea was intubated, and assisted ventilation was started because of transient tachypnoea of the newborn. At 3 days of age, the patient developed fever. Empiric antibiotic treatment was started. On the following day, measles-like exanthema and thrombocytopenia developed. At 6 days of age, the patient had a yellowish tracheal secretion, and laryngoscopy showed her glottis to be red but not swollen. A diagnosis of acute laryngotracheitis was made. EDIN-producing MRSA were isolated from the tracheal secretion but not from blood. The patient recovered from the systemic illness which was diagnosed as NTED. At 10 days of age, extubation was attempted; however, the patient had to be reintubated soon after because of severe stridor and retraction. Further attempts at extubation using adrenaline inhalation and systemic steroids were also unsuccessful. A bronchoscopy disclosed subglottic stenosis due to granulation tissue, and tracheotomy was performed.

\section{Discussion}

The pathogenesis of ASGS is related to traumatic injury caused by endotracheal intubation. It is impossible to avoid minor trauma of the subglottis even if patients are intubated carefully. The immediate pathological changes of mucosal oedema, hyperaemia, ulceration, 
mucosal necrosis, production of granulation tissue with various degrees of fibroblastic response, and re-epithelialisation of ulcerated tissue have been described in a number of studies. ${ }^{37}$ It has recently been suggested that spreading of cells at the edge of the wound surface and migration of epithelial cells are key events in the repair process, and that the actin cytoskeleton in migrating cells is essential. ${ }^{8}$

EDIN is an exoenzyme from $S$ aureus that ADP-ribosylates the Ras-like small GTPbinding protein, Rho. The kinetics of ADPribosylation of Rho by EDIN are very similar to those of C3 ADP-ribosyltransferase from Clostridium botulinum. ${ }^{6}$ Ras-related GTPases from the Rho family organise the actin cytoskeleton and focal adhesion formation. ${ }^{9}$ EDIN and C3 inhibit the actin cytoskeleton and focal adhesion formation as well as differentiation of keratinocyte by ADP-ribosylation of Rho. ${ }^{10}$ In experimental medicine, there have been many reports on EDIN, but this is the first of EDIN associated disease. ${ }^{561011}$

In wound repair models using endothelial cell cultures, EDIN was found to block wound repair. ${ }^{12}$ Endothelial cell migration is a critical event in the repair of injured blood vessels. EDIN ADP-ribosylates Rho in the endothelial cell, which abolishes the formation of actin stress fibre/focal adhesions, which is essential for endothelial cell migration.

In wound repair of the subglottis, epithelial cell migration is a critical event, similar to endothelial cell migration in the repair of injured blood vessel. ${ }^{8}$ Recently Rho has been shown to be expressed by human airway epithelial cells. ${ }^{13}$ The presence of Rho in human airway epithelial cells suggests that EDIN inhibits epithelial cell migration and subsequent wound repair by inactivating Rho. ASGS in our cases may be the result of delayed wound healing because of EDIN inhibition of the migration of epithelial cells.

The staphylococcal strains isolated in these two cases not only produce EDIN but are also the pathogens responsible for another systemic disease reported in neonates. Reports of NTED, a newly discovered disease in neonates characterised by fever, exanthema, and thrombocytopenia, have increased in Japan since its initial description in 1997 by Takahashi et al. ${ }^{14} 15$ TSST-1, one of the superantigenic exotoxins produced by MRSA, was isolated from almost all the patients with NTED ${ }^{15}$ Both of our patients were diagnosed as having NTED, and the MRSA isolated from our patients produced not only EDIN but also TSST-1. In the patients with NTED, serious complications such as mucosal damage were seen in many who were preterm, but were rare in full term infants. ${ }^{14} 15$ Therefore it is unlikely that, in the full term patients described here, the cause of ASGS was NTED. Although it has been suggested that EDIN is related to staphylococcal skin lesions, the relation between EDIN and NTED or TSST-1 has not yet been clarified. ${ }^{11}$

Carriage of MRSA is common among neonates in Japan. The prevalence of EDINproducing strains of $S$ aureus in neonatal intensive care units has not yet been studied, but $12 \%$ of 113 general clinical isolates in Japan have been reported to produce EDIN. The prevalence of EDIN-producing strains on neonatal units is of major clinical importance, if we are correct in our speculation that this toxin delays wound healing and may lead to serious pathology.

We are grateful to Dr H Ikeda (Department of Otolaryngology, Kansai Medical University Otokoyama Hospital) and Dr K Maeda (Department of Pediatric Surgery, Takatsuki General Hospital) for their help with performing the laryngoscopy and bronchoscopy, to Dr T Sasaki (Department of Pediatrics, Kansai Medical University Otokoyama Hospital) for her important contribution, and to Dr W Minamide (Osaka Laboratories, Shionogi Biomedical Co, Ltd) for helpful discussions and encouragement. We also thank Professor Y Kobayashi (Department of Pediatrics, Kansai Medical University) for his suggestions and criticism of this work.

1 Puhakka HJ, Kero P, Valli E, Iisalo E, Erkinjuntti M. Subglottic stenosis in neonates and children. Acta Paediatr Scand 1990;79:397-401.

2 Brown OE, Manning SC. Microbial flora of the subglottis in intubated pediatric patients. Int $\mathcal{F}$ Pediatr Otorhinolaryngol 1996;35:97-105.

3 Gould SJ, Howard S. The histopathology of the larynx in the neonate following endotracheal intubation. $F$ Pathol 1985; 146:301-11.

4 Contencin P, Narcy P. Study group for neonatology and pediatric emergencies in the Parisian area. Size of endotracheal tube and neonatal acquired subglottic stenosis. Arch Otolaryngol Head Neck Surg 1993;119:815-19.

5 Sugai M, Enomoto T, Hashimoto K, et al. A novel epidermal cell differentiation inhibitor (EDIN): purification and
characterization from Staphylococcus aureus. Biochem Biophys Res Commun 1990;173:92-8.

6 Sugai M, Hashimoto K, Kikuchi A, et al. Epidermal cell differentiation inhibitor ADP-ribosylates small GTP-binding proteins and induces hyperplasia of epidermidis. $\mathcal{F} \mathrm{Biol}$ Chem 1992;267:2600-4.

7 Gould SJ, Young M. Subglottic ulceration and healing following endotracheal intubation in the neonate: a morphometric study. Ann Otol Rhinol Laryngol 1992;101:815-20.

8 Zahm JM, Chevillard M, Puchelle E. Wound repair of human surface respiratory epithelium. Am $\mathcal{F}$ Respir Cell Mol Biol 1991;5:242-8.

9 Hall A. Small GTP-binding proteins and the regulation of the actin cytoskeleton. Annu Rev Cell Biol 1994;10:31-54.

10 Hatazaki K, Sugai M, Momota H, Ohgai H, Komatuzawa $\mathrm{H}$, Suginaka $\mathrm{H}$. Expression and purification of epidermal cell differentiation inhibitor (EDIN) from Bacillus subtilis. Protein Expres Purif 1998;12:284-90.

11 Sugai M. Epidermal cell differentiation inhibitor: a novel ADP-ribosyltransferase from Staphylococcas aureus. In: Mollby R, Flock I, eds. Staphylococci and staphylococcal
infections. Stuttgart: Gustav Fischer Verlag, 1994:267-76.

12 Aepfelbacher M, Essler M, Huber E, Sugai M, Weber PC. Bacterial toxin block endothelial wound repair: evidence that Rho GTPases control cytoskeletal rearrangements in that Rho GTPases control cytoskeletal rearrangements in
migrating endothelial cells. Arterioscler Thromb Vasc Biol migrating endotheli

13 Pan ZK, Ye RD, Christiansen SC, Jagels MA, Bokoch GM, Zuraw BL. Role of Rho GTPase in bradykinin-stimulated nuclear factor- $\kappa \mathrm{B}$ activation and IL-1 $\beta$ gene expression in cultured human epithelial cells. $\mathcal{f}$ Immunol 1998;160:3038-45

14 Takahashi N, Nishida H. New exanthematous disease with thrombocytopenia in neonates. Arch Dis Child Fetal Neonatal Ed 1997;77:F79.

15 Takahashi N, Nishida H, Kato H, Imanishi K, Sakata Y, Uchiyama T. Exanthematous disease induced by toxic shock syndrome toxin 1 in the early neonatal period. Lancet 1998;351:1614-19. 